Editorial

\title{
Acts and omissions revisited
}

Tony Hope Oxford University, Oxford

There are some ideas that at first seem simple, but which become more complex and profound the more they are explored. Great art, of course, is like that. When I first saw Vermeer's Girl with a Pearl Earring I was excited by its fresh simplicity. I thought, however, it a painting I would soon understand. I was wrong. It becomes increasingly mysterious with increasing familiarity. It has recently inspired a novel. ${ }^{1}$

The distinction between acts and omissions is one of these simple, complex, ideas. When I first studied philosophy I thought I would rapidly be able to decide once and for all whether the distinction is of moral importance or not. I did in fact come to a decision. The problem is that I have kept revising that decision ever since. The issues raised by the arguments over acts and omissions continue to inspire philosophical discussion. They also continue to haunt doctors and relatives at the bedsides of those near the end of their lives.

Donna Dickenson, in this issue of the journal, ${ }^{2}$ reports the results of a survey of opinions from those taking part in an Open University course on death and dying. She believes that for many bioethicists the acts/omissions distinction has been shown to be wrong as a distinction of moral worth. Her survey suggests, however, that for many health professionals this distinction is seen as morally important. She asks whether the bioethical consensus, as she sees it, against the distinction is a result of clear thinking, or whether the views of practitioners result from their taking into account, in a way bioethicists do not, the richness of reality.

There is I believe, less consensus amongst bioethicists than Dickenson suggests. In this issue of the journal, Marc Stauch ${ }^{3}$ argues in favour of the acts/omissions distinction.

According to the acts/omissions distinction, "in certain contexts, failure to perform an act, with certain foreseen bad consequences of that failure, is morally less bad than to perform a different act which has the identical foreseen bad consequences. It is worse to kill someone than to let them die". ${ }^{4}$

The case against the distinction has been graphically put by Rachels. ${ }^{5}$ Rachels asks us to imagine two cases. In case 1, Smith sneaks into the bathroom of his six-year-old cousin and drowns him, arranging things so that it will look like an accident. The reason Smith does this is that the death of his cousin results in his benefiting from a large inheritance. In case 2, Jones stands to gain a similar large inheritance from the death of his six-year-old cousin. Like Smith, Jones sneaks into the bathroom with the intention of drowning his cousin. His cousin, however, accidentally slips and knocks his head and drowns in the bath. Jones could easily have saved his cousin, but far from trying to save him, he stands ready to push the child's head back under the water. However, this does not prove necessary.

This pair of cases is a kind of controlled experiment in moral thinking. Everything is kept the same in the two cases-the intention, the consequences - except that in one case Smith acts to cause the death of the child, and in the other case, Jones omits to act in order to cause the death of the child. The reader, it is assumed, will believe that Smith and Jones are equally culpable for the death of the child from a moral (if not a legal) point of view. If this is the case, then the distinction between acts and omissions itself cannot be of moral significance.

There is another pair of cases, however, which speaks for the other side. ${ }^{6}$ Robinson (let us say) does not give $£ 100$ to a charity which is helping to combat starvation in a poor country. As a result one person dies of starvation who would have lived had Robinson sent the money. Davies, on the other hand, does send $£ 100$ but also sends a poisoned food parcel for use by a charity distributing food donations. The overall and intended result is that one person is killed from the poisoned food parcel and another person's life is saved by the $£ 100$ donation. Taken overall the omission to send money by Robinson, and the acts of sending the poison and giving money to charity by Davies lead to the same overall consequences in terms of number of lives lost. Robinson has let a person die through failure to act, Davies has killed a person. And in this case there seems an enormous moral difference. Robinson is like most of us; Davies is a vile murderer.

In the most original part of his paper, Stauch argues that there is a moral basis for considering that omitting to save life may be right, but actively killing is wrong even when all consequences are the same. In contrast with the two examples above, Stauch is concerned with situations where the motives, and outcomes, in both cases are good.

Stauch makes two claims. First, each life possesses irreducible value, by which he means: "a value that cannot be fully cashed out in terms of the 
life-holder's own states of consciousness, pleasurable or otherwise". Thus, even when the person would prefer to be dead, or is suffering greatly, or has no conscious experience at all and no prospect of such experience, there is some value in the life. In saying this Stauch is not claiming that this "irreducible value" necessarily outweighs all the bad aspects of the life. Indeed, a doctor may rightly withhold treatment on the grounds that it does not. How then does this irreducible value uphold a moral distinction between acts and omissions? Stauch's answer lies in his second claim which he calls the "equality principle". According to this principle "the life of each individual has an equal claim to a minimum respect by possessing irreducible value" (as explained above). "An agent who engages in active euthanasia (even at the behest of the deceased) fails to show this respect, for, in assuming authorship over that other's death, he automatically accords his own life an ontological priority: he draws upon his own resources (for which his life is, of course, a precondition) in such a way as to extinguish the life of the other."

This argument has two parts. First is the use of the acts/omissions distinction to underpin the idea of authorship. Thus the doctor who (for good reasons) withdraws treatment is not the author of the death; whereas the doctor who injects potassium chloride is the author of the patient's death. But the question remains, why should this make a moral difference? Stauch's answer is based on equity. If I act (for the best of reasons) so that another (for example, a patient) dies then I have given more weight to the irreducible value of my own life than the weight that I have given to the irreducible value of the other person's life - and this is inequitable. However, if I omit to act for the same reasons and with the same outcome, I have not given more weight to the value of my own life. If I have understood Stauch correctly this is because in order to act I need to be alive (if this is what Stauch means by "for which his life is ... a precondition"); whereas to omit to act I need not be alive (in the sense, I presume, that the omission would occur even if I suddenly ceased to exist). This is problematic. For one thing, it draws the acts/omissions dis- tinction where Stauch does not want to draw it. The doctor who withdraws life-support draws upon his own resources - so withdrawal would count as an act, and not an omission. Second, and more important, it is not at all clear to me what it means to say that I give ontological priority to my life when I act, but not when I omit to act. I can understand that, in a situation where one life is sacrificed for the sake of another life, then it might be said that the second life is given priority over the first. But where it is not a question of choosing between the two lives, I don't understand the meaning of "ontological priority". Suppose the doctor decides (correctly) that overall it would be best for the patient to die. I do not understand in what sense the doctor is giving priority to his own life's value against that of the patient, whether the patient's death is brought about by an act or by an omission. The doctor's life is not in the balance.

The question of whether there are moral differences between withholding and withdrawing treatments, or between acts and omissions is, as Dickenson's survey shows, one on which nurses, and I imagine doctors, disagree. Stauch's article demonstrates that there is still philosophical and legal life left in analysing the moral and conceptual implications of these issues.

Tony Hope is Editorial Associate of the Journal of Medical Ethics and Reader in Medicine, Oxford University, UK.

\section{References and notes}

1 Chevalier T. Girl with a pearl earring. London: Harper Collins, 1999.

2 Dickenson D. Are medical ethicists out of touch? Practitioner attitudes in the US and UK towards decisions at the end of life. Fournal of Medical Ethics 2000;26:

3 Stauch M. Causal authorship and the equality principle: a defence of the acts/omissions distinction in euthanasia. Fournal of Medical Ethics 2000;26:254-60.

4 Glover J. Causing death and saving lives. Harmondsworth: Penguin, 1977: 92-3.

5 Rachels J. Active and passive euthanasia. New England fournal of Medicine 1975;292:78-80. Reprinted in: Singer P, ed. Applied of Medicine 1975;292:78-80. Reprinted in: Sin
ethics. Oxford: Oxford University Press, 1986.

6 These cases are based on Foot P. The problem of abortion and doctrine of double effect, quoted in Glover J. Causing death and saving lives. See reference 4 . 